\title{
HUMAN FACTORS IN VISUAL QUALITY CONTROL
}

\author{
Agnieszka Kujawińska, Katarzyna Vogt \\ Poznan University of Technology, Faculty of Mechanical Engineering and Management, Poland \\ Corresponding author: \\ Agnieszka Kujawińska \\ Poznań University of Technology \\ Faculty of Mechanical Engineering and Management \\ Piotrowo 3, 61-138 Poznań, Poland \\ phone: $(+48) 61665-27-38$ \\ e-mail: agnieszka.kujawinska@put.poznan.pl
}

Received: 30 April 2015

Accepted: 8 May 2015

\begin{abstract}
Visual control (visual inspection) is often used in production because - in comparison to other kinds of control - it is relatively easy to conduct. It does not require any specialized technical equipment. Human senses, usually sight, are the measurement tool. Unfortunately, visual control does not guarantee a fully correct assessment. The reason is the limited human reliability. There are plenty of factors which influence ability of a human to assess the process or product quality properly. An important group of them are ergonomic factors. The goal of the paper is to identify and discuss their influence on the efficiency of the visual quality control in manufacturing processes.

The research was carried out in manufacturing company from automotive industry. The paper presents the investigation of work organizational factors influence on visual control effectiveness. A controller can make two types of errors in the process of visual inspection: to assess a conforming product as "defective" or to assess a non-conforming product as "good". Effectiveness of sequential visual controls in selected process was examined. As a measure of visual control effectiveness Control First Pass Yield index was defended. Three operations were analyzed: assembly of components, melting components and applying a protective coating.
\end{abstract}

KEYWORDS

production, process efficiency, visual inspection.

\section{Quality control}

Controlling is one of the four major functions of management, together with planning, organizing, and leading. Among different types of controlling in production companies quality control is of particular importance, as it aims at checking process or product compliance with the requirements of an internal or external customer $[1,2]$.

Quality control in production processes consists in the evaluation of one or more features of the product, and comparing the result with the expectations. Quality control may be divided into different types, one of them being the division into the control of measurable (quantitative) and immeasurable (qualitative) features. The other is frequently referred to as alternative or attributable control [3-5].

Alternative product assessment is used when a direct or indirect measurement of a given product feature, expressed with a numerical value, is either impossible, difficult or cost ineffective. The outcome of the alternative assessment does not provide information on the extent to which the examined feature complies with requirements; it is the basis for a decision whether a given product may be considered "good" or if it should be rejected and regarded as poorly made, "bad" (defective). Therefore, the decision whether a product meets or fails to meet the specific requirements most often leads to the product being classified to one of the two (rarely more) conditions.

Alternative control may be performed using specialized equipment, which classifies products automatically (e.g. pattern-recognizing machines which verify $\mathrm{PCB}$, devices evaluating the colour of print etc.), or exclusively with the use of human senses. The other method is usually called organoleptic control. Visual inspection is a particular example of such control. 


\section{Visual inspection}

At the beginning of the 20th century visual inspection conducted by a man was considered as one of the most reliable among the alternative quality control methods (see Table 1). However, the view was challenged in 1950s - 1970s, when it was understood that the man is the weakest link in the quality control process. Thus, one of the major trends in the research on visual quality control at the time focused on complete automation of the control process by replacing the man with a machine [6].

Table 1

Research trends in visual inspection [6-9].

\begin{tabular}{c|l}
\hline Years & Selected research trends \\
\hline $1950 \mathrm{~s}$ & Visual inspection analysis \\
\hline $1960 \mathrm{~s}$ & $\begin{array}{l}\text { Development of techniques for the assessment } \\
\text { of visual inspection performed by inspectors }\end{array}$ \\
\hline $1970 \mathrm{~s}$ & $\begin{array}{l}\text { Development of signal detection theory and } \\
\text { mathematical models of visual inspection }\end{array}$ \\
\hline $1980 \mathrm{~s}$ & $\begin{array}{l}\text { Continuation of research on the automation of } \\
\text { visual inspection } \\
\text { Development of inspector selection techniques }\end{array}$ \\
\hline 2000 & $\begin{array}{l}\text { Computer-aided visual inspection (instruc- } \\
\text { tions) } \\
\text { Investigation of visual inspection reliability in } \\
\text { aviation industry }\end{array}$ \\
\hline 2010 & $\begin{array}{l}\text { Continuation of research on the automation of } \\
\text { visual inspection } \\
\text { The use of virtual reality in the training of }\end{array}$ \\
\hline
\end{tabular}

This was conducive to the development of automated vision systems. It turned out however, that successful implementation of such systems into industrial practice is not always possible (1980s and 1990s). One of the many reasons for that was and still is the limited flexibility of automated vision systems, which becomes particularly evident in new, non-standard situations, which were not taken into account at the system design stage. Today at incoming quality control, inter-operational in many production processes, visual inspection requires human assessment. In the last decade research in this area has focused mainly on the development of techniques supporting human visual inspection (Table 1) [6-9].

Today it is recognized that visual inspection is economically viable: it does not require the use of expensive equipment, and it's a non-destructive method, which means that it does not lead to the wear and tear of the inspected product. Still, using visual inspection and keeping in mind its strengths, one may not disregard its weakness: it is fallible, and does not guarantee $100 \%$ correct assessment [10].
The thesis is corroborated by numerous studies conducted at different times by different researchers (Table 2). Drury stated that inspection error is a fact of life but it can be reduced with appropriate interventions, such as employee training, better instructions, improvement of work conditions etc. [10]. For example, Swain and Guttman [6] estimated that the visual inspection error rate in simple control tasks appears to be on the order of $3-10 \%$. Drury, Karawanu and Vanderwarker suggest that the error rate may in fact be much higher and range from $20 \%$ to $30 \%$ of incorrect classification [6].

Table 2

The effectiveness of visual inspection in actual processes examples [10].

\begin{tabular}{l|l|c}
\hline Researcher & Process & $\begin{array}{c}\text { Effectiveness } \\
\text { of inspection } \\
{[\%]}\end{array}$ \\
\hline $\begin{array}{l}\text { Jacobson } \\
(1952)\end{array}$ & $\begin{array}{l}\text { Inspection of soldering } \\
\text { defects }\end{array}$ & $45-100$ \\
\hline $\begin{array}{l}\text { Heida } \\
(1989)\end{array}$ & $\begin{array}{l}\text { Aircraft landing gear } \\
\text { inspection }\end{array}$ & $57-98$ \\
\hline $\begin{array}{l}\text { Drury } \\
\text { et al. (1997) }\end{array}$ & $\begin{array}{l}\text { Aircraft visual inspec- } \\
\text { tion }\end{array}$ & 68 \\
\hline $\begin{array}{l}\text { Leach } \\
\text { and Morris } \\
(1998)\end{array}$ & $\begin{array}{l}\text { Visual inspection of } \\
\text { subsea structures and } \\
\text { pipelines }\end{array}$ & 53 \\
\hline $\begin{array}{l}\text { Graybeal } \\
\text { et al. (2002) }\end{array}$ & $\begin{array}{l}\text { Routine inspection of } \\
\text { highway bridges }\end{array}$ & 52 \\
\hline
\end{tabular}

Visual inspection may be conducted by a man, a machine or a hybrid: man-machine. Studies conducted by Jiang demonstrated that a man-machine combination is the best solution for such control in terms of cost effectiveness. He also stated that human participation is crucial at the stage of decision making, when the product is classified to the appropriate group, e.g. to "good" or "defective" products.

\section{Visual inspection process - structure and effectiveness}

The structure of the visual inspection process is one of the most important features that influences its effectiveness [10]. According to Fox [11], from the work process perspective visual inspection consists of several stages:

- visual "screening"/search for potential defects,

- finding a defect ("detection"),

- defect classification,

- decision that classifies a component, product or service.

Each of the stages has an impact on the effectiveness of inspection. The first stage, when an object is visually examined by a man, requires vigilance, heightened sensitivity of sight to detect poten- 
tial errors. In the first and second stage of inspection, when the level of inspector's perception is of particular significance, appropriate working conditions and inspector's knowledge about potential defects are absolutely required.

In the third stage, based on his knowledge about the defects and classification criteria, the inspector makes the decision on the type of defect detected in the product.

In the final part of the inspection process the inspector decides if the product may be forwarded to further steps of the process, or if it should be separated from good quality products.

Two of the four stages mentioned above (searching for defects and decision-making) seem to be of particular importance from the point of view of visual control. It turns out that they are most exposed to decision variability of the operators. In the inspection process they may make two types of errors (Table 3): classify a good quality product as defective (FALS) and classify a defective product as good (MISS).

Table 3

Four possible human decisions in visual inspection of products [4].

\begin{tabular}{c|c|c}
\hline & \multicolumn{2}{|c}{ Actual condition of product } \\
\hline Decision & $\begin{array}{c}\text { Defective product } \\
\text { (NOK) }\end{array}$ & $\begin{array}{c}\text { Good quality } \\
\text { product } \\
\text { (OK) }\end{array}$ \\
\hline Rejection & $\begin{array}{c}\text { Correct decision: } \\
\text { Product rejection }\end{array}$ & $\begin{array}{c}\text { Incorrect decision: } \\
\text { product rejection } \\
\text { (FALSE ALARM) }\end{array}$ \\
\hline & $\begin{array}{c}\text { Incorrect decision: } \\
\text { product approval } \\
\text { (MISS) }\end{array}$ & $\begin{array}{c}\text { Correct decision: } \\
\text { product approval }\end{array}$ \\
\hline
\end{tabular}

The likelihood of committing these two types of errors and the fraction of products that do not conform with requirements after the inspection process are the key indicators of inspection efficiency $[12,13]$.

In the literature there are many measures for the effectiveness of visual inspection [12], among others the ratio of Freeman-McCornack, Youden-Nelson, Wallack-Adams.

In the second part of this paper we use the $\mathrm{CE}$ - Control Efficiency index, which is a percentage of detected defects and an original index control First Pass Yield (cFPY), which defines the share of defects found during the first inspection in the total number of defects at the given stage of the process, expressed as a percentage.

$$
\mathrm{cFPY}=\frac{a^{*}}{b^{*}}
$$

where $a^{*}$ - number of defects found during the first inspection $* 100 \%, b^{*}$ - total number of defects at the given stage of the process.
The maximum value of cFPY (100\%) for an inspection means that every defect is detected at the stage when it should be detected. That means that no defect enters further stages of the process. Low cFPY indicates that a given inspection is ineffective. The majority of defects which should be detected by a given inspection are only detected in further stages of the process, by secondary inspections (occurring later in the process sequence) or are not detected at all.

\section{Factors affecting the efficiency of visual inspection}

There are many factors that affect the efficiency of visual inspection. Making the decision concerning the quality of inspected products requires not only a specific knowledge of the industry, but often also individual approach to every inspected product and high sensitivity to defects.

Relevant research shows that the efficiency of visual inspection is affected by independent factors and factors related to and dependent on man (Fig. 1) [6, $7,9,14]$. These two main groups of factors can be divided into five categories, as shown in Table 4.

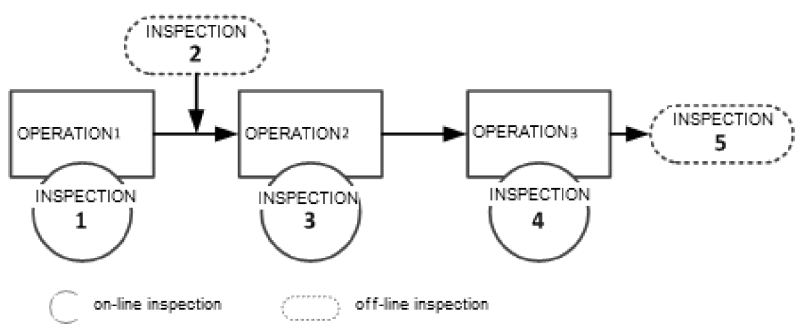

Fig. 1. Operations and interventions in the analyzed process [own work].

Table 4

Factors affecting visual inspection efficiency $[6,7,9,14]$.

\begin{tabular}{l|l}
\hline Factors & Examples \\
\hline Technical & $\begin{array}{l}\text { Type of defects; Defect visibility; Qual- } \\
\text { ity level; Standards (tests); Control au- } \\
\text { tomation; Other }\end{array}$ \\
\hline Psychophysical & $\begin{array}{l}\text { Age; Sex; Observation skills; Experi- } \\
\text { ence; Temperament; Creativity; Other }\end{array}$ \\
\hline Organizational & $\begin{array}{l}\text { Training; Scope of decision making; } \\
\text { Feedback; Precise instructions; Other }\end{array}$ \\
\hline Workplace & $\begin{array}{l}\text { Light; Noise; Temperature; Work time; } \\
\text { Workstation organization; Other }\end{array}$ \\
\hline Social & $\begin{array}{l}\text { Team communication; Pressure; Isola- } \\
\text { tion; Other }\end{array}$ \\
\hline
\end{tabular}

Technical factors are associated with the physical execution of visual inspection in the production process. They include, for example, factors related to the actual quality level, product features subject to inspection (their accessibility for visual inspection), 
to the standards, based on which the product is controlled, the availability of tools used during the inspection, etc.

Psychophysical factors are associated with mental and physical conditions of inspectors. These include age, sex, intelligence, temperament, health condition etc. Research in this area aims at identifying the characteristics comprising the profile of the ideal inspector.

The next group of factors affecting the effectiveness of visual inspection are organizational factors. These include support in decision-making during the inspection, acquiring inspector skills, number and type of inspections, information on efficiency and accuracy of conducted inspections, as well as stress factors influencing the inspector, such as time, consequences of incorrect assessment (no bonus, loss of company image, etc.).

Workplace environment conditions are associated with the workplace, where the inspection takes place. These include physical factors, such as light, noise, temperature, as well as the organization of the workstation itself.

The last group comprises factors related to the social environment, where inspectors work. Their work often involves pressure from people, whose interest is contrary to the inspector's work. For example, production staff (often colleagues) exert pressure expecting approval of their work (which is related to the payment of salaries, bonuses). In turn, employees of the management board may exert pressure to minimize reinspections of products with unambiguous assessment.

\section{Case study}

\section{Research methodology}

To determine the influence of selected abovementioned factors on inspection efficiency, a study was carried out for three operations in the PCB production process.

The study focused on the visual inspection processes during the assembly and soldering of components, and the application of protective coating. $\mathrm{CE}$ - Control Efficiency was chosen as the effectiveness index, expressed as a fraction of detected defects and the cFPY measure. The study was conducted over 32 weeks.

Three interventions took place in the examined production process (Fig. 1):

- operation 1: assembly and soldering of throughhole components,

- operation 2: application of protective coating on the $\mathrm{PCB}$
- operation 3: functional test.

For a given process, five control operations have been distinguished (Fig. 1):

- inspection 1: performed by the operator during the assembly and soldering of components - online;

- inspection 2: performed in an separate location by the inspector - interoperational off-line;

- inspection 3: performed by the operator during the application of the protective coating - on-line;

- inspection 4: performed in the functional test operation - on-line;

- inspection 5: performed in a separate location by the inspector - off-line.

The sources of possible defects in the process include operation 1 , operation 2 , and component supplier (Table 5). Defects that originate in the assembly and soldering of components (operation 1) may include: lack of component, incorrect assembly of the component, component is not lead through and outside the assembly hole, excess of solder, lack of solder, and other. We assumed that the defects should be first detected at inspection 1 and inspection 2. They are also detected by inspection 4 and 5 (secondary detection).

Table 5

The matrix of operations and visual inspections in the process and locations where the categorized defects originate and are detected (Symbols: I - defects in component assembly; II - defects in component soldering process; III defects in protective coating; IV - impurities; V - defects related to component quality. $\mathrm{P}$ - place where defect originated; PW - location where the defect should have been detected during the first inspection; WW - location of detection during re-inspection, when a defect was moved to subsequent stages of the process).

\begin{tabular}{|c|c|c|c|c|c|}
\hline Name of operation/inspection & I & II & III & IV & V \\
\hline $\begin{array}{l}\text { OPERATION } 1 \text { (OP1) } \\
\text { Assembly and soldering of } \\
\text { components }\end{array}$ & $\mathbf{P}$ & $\mathbf{P}$ & & & \\
\hline INSPECTION 1 (I1) & PW & PW & & PW & PW \\
\hline INSPECTION 2 (I2) & PW & PW & & PW & PW \\
\hline $\begin{array}{l}\text { OPERATION } 2 \text { (OP2) } \\
\text { Application of protective } \\
\text { coating }\end{array}$ & & & $\mathbf{P}$ & & \\
\hline INSPECTION 3 (I3) & & & PW & & \\
\hline $\begin{array}{l}\text { OPERATION } 3 \text { (OP3) } \\
\text { Functional test }\end{array}$ & $\begin{array}{l}\mathbf{W} \\
\mathbf{W}\end{array}$ & $\begin{array}{l}\mathbf{W} \\
\mathbf{W} \\
\end{array}$ & & & \\
\hline INSPECTION 4 (I4) & & $\begin{array}{l}\mathbf{W} \\
\mathbf{W}\end{array}$ & $\begin{array}{l}\mathbf{W} \\
\mathbf{W}\end{array}$ & $\begin{array}{l}\mathbf{W} \\
\mathbf{W}\end{array}$ & \\
\hline INSPECTION 5 (I5) & $\begin{array}{l}\mathbf{W} \\
\mathbf{W}\end{array}$ & $\begin{array}{l}\mathbf{W} \\
\mathbf{W}\end{array}$ & $\begin{array}{l}\mathbf{W} \\
\mathbf{W}\end{array}$ & $\begin{array}{l}\mathbf{W} \\
\mathbf{W}\end{array}$ & $\begin{array}{l}\mathbf{W} \\
\mathbf{W}\end{array}$ \\
\hline
\end{tabular}

Defects in the operation application of protective coating may include coating in prohibited area of the circuit and lack of coating. It was assumed that the 
defects should be detected during inspection 3, i.e. by the operator applying the coating. Defects originating in this operation are also detected in inspection 4 and final (5) inspection.

Defects related to impurities and inappropriate quality of components originate at the supplier. We assumed that the defects should be first detected at inspection 1 and inspection 2 .

In the experiment we identified 4165 defects, including 400 defects associated with assembly errors, 1053 defects related to soldering, 1207 defects resulting from the application of coating, 1395 defects associated with impurities and 110 defects of unacceptable component quality.

One hundred percent of PCBs were inspected. The operator verified objects at $4 \mathrm{x}$ magnification, and in uncertain cases, at 10x magnification. An identified defect was qualified and directed to destruction (unrepairable defective products) or to repair (repairable defects).

Analysis of each inspection effectiveness was conducted for the five categories of defects given in Table 5 according to the organization and type of inspection (on-line and off-line), defect location (known and unknown defect location) and work shift $(1,2$, and 3 shift). As a measure of effectiveness we adopted the percentage of defects detected in the given inspection $(\mathrm{CE})$, and the $\mathrm{cFPY}$ index.

The cFPY is determined only twice: for inspection 1 and 2, and inspection 3. (Fig. 2). For the first two inspections we assumed that four categories of defects should be detected: defects of assembly, soldering, impurities, and quality of components. They appear at this inspection point for the first time.

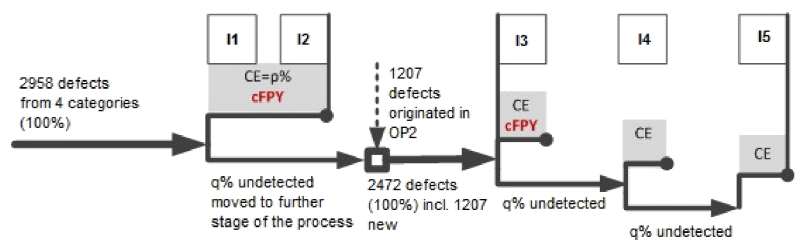

Fig. 2. Flow chart of quality control in the analyzed process (Symbols: p\% - percentage of defects detected at a given stage (CE), cFPY - control First Pass Yield, $\mathrm{q} \%$ - percentage of undetected defects).

In the case of inspection 3 the cFPY index is calculated only for the defects related to the protective coating - their first occurrence.

For all control operations we also calculated the percentage of undetected defects (the so-called control efficiency, CE) in relation to all defects which occurred at the entry to the inspection process. It should be noted that for inspection 1 and 2 the basis for determining the fraction of defects detected was the number of defects related to four categories, while for inspection 3,4 and 5 it was the total of defects that were not detected in previous inspections and defects concerning the coating which appeared in operation 3 .

\section{The organization and location of inspection and its effectiveness}

The organization and location of inspection is understood as its setting in the production process sequence. Two basic types of inspection have been distinguished: on-line andoff-line. On-line inspection is performed on an ongoing basis and it is one of the stages of the flow of semi-finished/finished products through the production line. Each time it accompanies a technological operation (e.g. assembly and soldering of components). Off-line inspection constitutes a separate stage of a process, it does not accompany any technological operation. As shown in Fig. 1, the process is divided into three on-line and two off-line inspections.

Comparing the value of the cFPY index for inspection 1 and 2, and for inspection 3, we may say they are relatively low (Fig. 3). For inspection 3, the value of this index was only $11 \%$. Such low level of effectiveness definitely results from the relation between the on-line inspection and the performed operation, which increases the risk of missing a defect. In the case of inspection 1 and 2 the cFPY value was higher: the operators found $28 \%$ and $40 \%$, respectively, of all defects which occurred for the first time. The value of the index was higher in inspection 2 , because the inspection was conducted off-line.

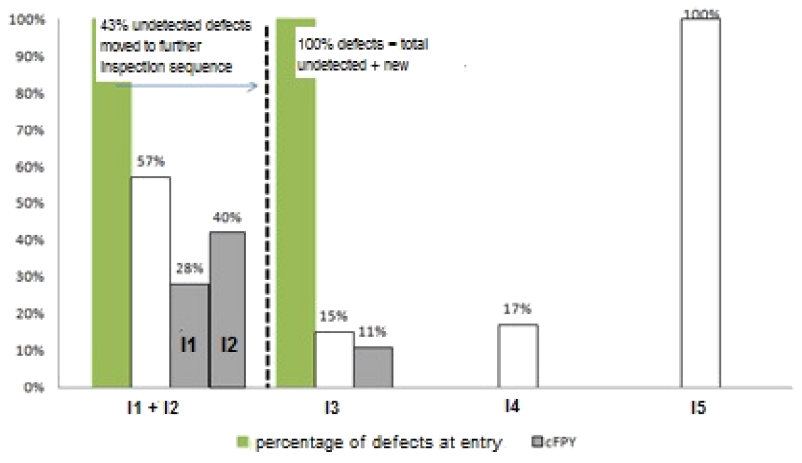

Fig. 3. The value of cFPY index and $\mathrm{CE}$ - fractions of detected defects for each inspection.

The percentage of detected defects expressed with the $\mathrm{CE}$ index in the on-line inspection was very low: $15 \%$ and $17 \%$. Off-line inspections proved much more effective, particularly the final inspection, when all defects which "entered" the control operation were detected. 


\section{Defect location and its influence on inspection efficiency}

We distinguished two types of defect detection complexity level in printed circuits. As regards the

4A. Defects of known location: assembly and soldering defects
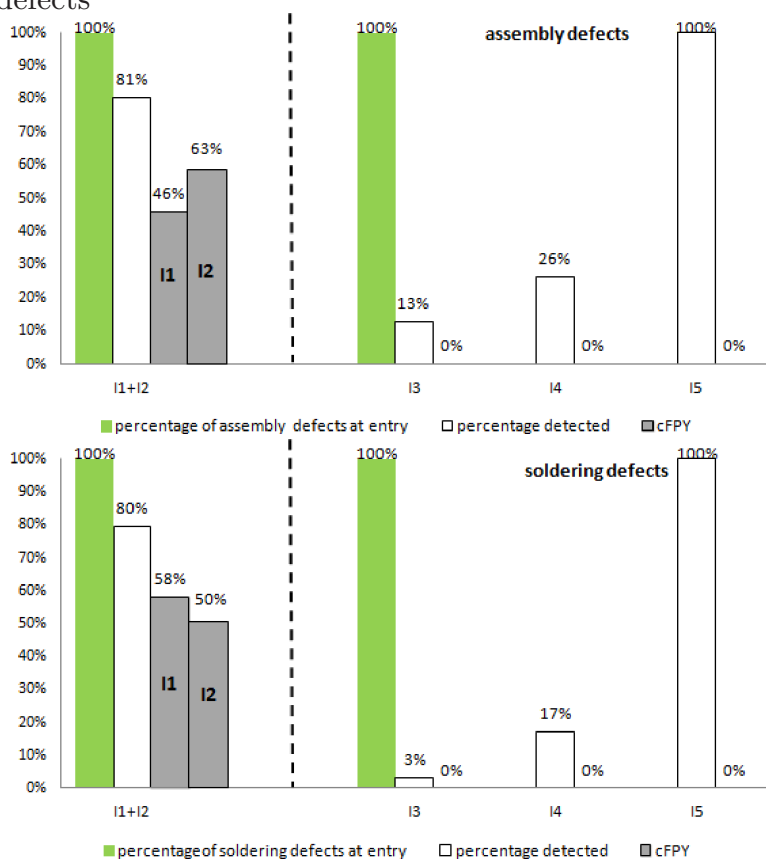

4B. Defects of unknown location: coating and impurity
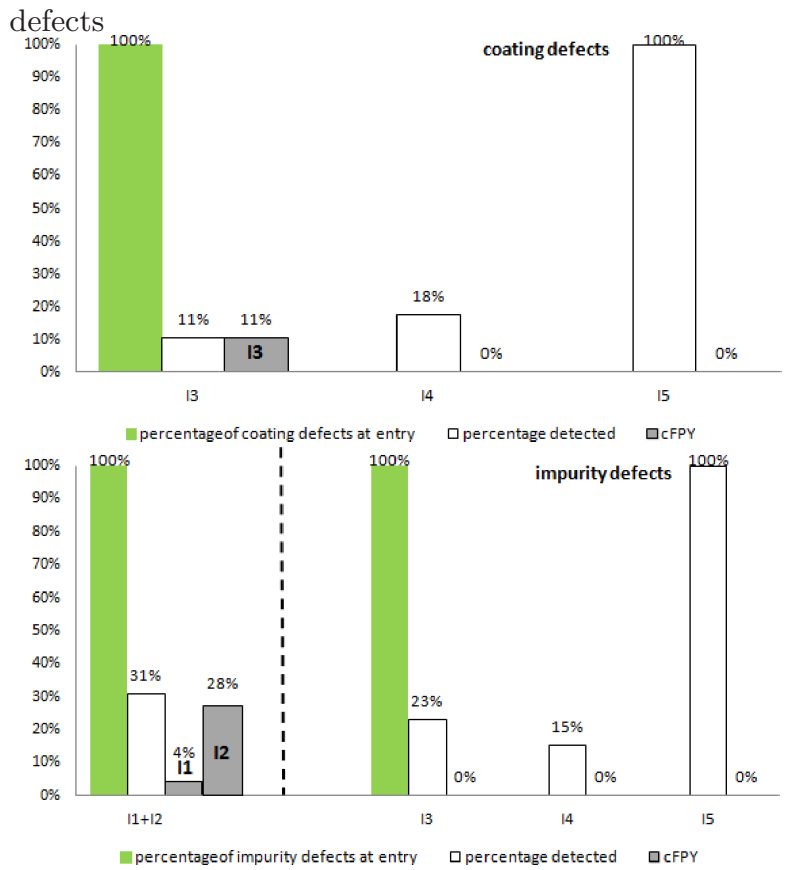

Fig. 4. Value of the cFPY index and fraction of errors for defects of known and unknown location in the process of assembly, soldering, and coating (CE). location of the defect in the product, there are defects of known, repeatable location and defects of unknown, random location in the product. The first group includes defects resulting from the assembly and soldering, and other - defects related to impurities and quality of protective coating (Fig. 4).

Comparing the efficiency of each inspection based on the cFPY index value (Fig. 4) it should be noted that defects with constant location known to inspectors are detected most successfully. For comparison, at inspection stations no. 1 and 2 operators detect as much as $81 \%$ of all assembly defects, $80 \%$ of all soldering defects, and only $31 \%$ of all defects related to impurities. In the case of defects of the protective coating, for inspection 3 the index is very low at only $11 \%$.

Defects that are difficult to predict, with random location on the circuit, are a much greater challenge for operators in the product evaluation process.

\section{Work shift and its impact on inspection effec-} tivenes

The company works a three-shift schedule. Analyzing the influence of the shift system on inspection effectiveness, we only focused on defects related to soldering and coating. Results of the analysis are shown in Fig. 5.

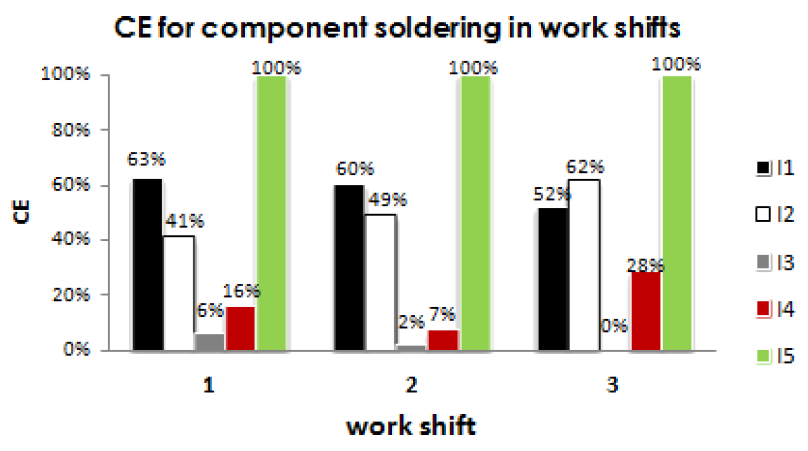

CE for coating defects in work shifts

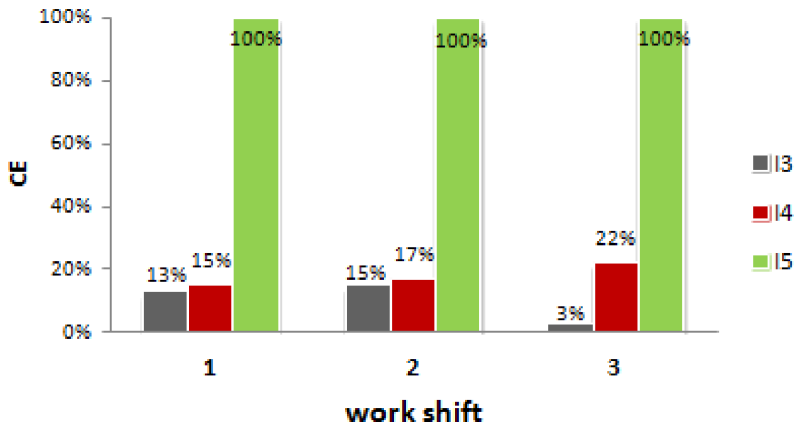

Fig. 5. Value of the FPY index for the soldering and coating process for different work shifts. 
Assessing the impact of the work shift on the effectiveness of inspection at workstations, one may note a certain trend: the effectiveness $(\mathrm{CE})$ increases with the progress of the production shift. For example, for defects in component soldering, the $\mathrm{CE}$ index in inspection 2 is $41 \%$ for the first shift, $49 \%$ for the second shift, and as much as $62 \%$ for the third (night) shift. Similarly, in inspection 4 the CE index for the first shift was $16 \%$ and for the third shift $-28 \%$. Only in inspection 3 (related to the detection of soldering defects on-line), the value of the CE index decreases. The night shift is not conducive to detecting such defects. The value of the CE index for inspection 3 is $13 \%$ for the first shift, $15 \%$ for second shift, and only $3 \%$ for the third shift. It turns out that the night shift is not conducive to the detection of defects of unknown location.

\section{Conclusions}

The effectiveness of visual quality control performed by a man is a complex issue, as it is influenced by many factors: both organizational and those related directly to the man.

The above was confirmed by the 32 -week long observation of visual inspections in the process of PCB production. Such factors as location of the inspection, defect type, and work shift were taken into account in the study.

When assessing the efficiency of inspection sequence with the CE and cFPY indexes for different types of defects it was noted that already at inspection 1 defects with known, repeatable location in the product are detected much more successfully. Defects with random location are usually detected as a result of a final control and require a comprehensive product assessment.

Additionally, we should note that the off-line control (e.g. no. 2 or 5 ) is more efficient than on-line, particularly for defects with a constant, repeatable location. Combining quality control interventions with the technological work disrupts the work of the operator. The risk of error in on-line control is greater than in the off-line control.

Moreover, differences in inspection efficiency during different work shifts result not only from the organization of work itself, but also from the psychophysical abilities of the man. This influence becomes apparent in the differences between the effi- ciency of control operations performed during the subsequent work shifts.

\section{References}

[1] Hamrol A., Quality Management with examples, PWN, Warsaw, 2008.

[2] Price P.S., Right First Time, Gower, London, 1985.

[3] Bauer J.E., Duffy G.Z., Westcott R.T., The Quality Improvement Handbook, Quality Press, Milwaukee, 2002.

[4] Oakland J.S., Statistical Process Control: A Practical Guide (5th Edition), Butterworth-Heinemann, Oxford, 2003.

[5] Wheeler D.J., Understanding Statistical Process Control, SPC Press, Knoxwille, 1992.

[6] Drury C.G., Sinclair M.A., Human and machine performance in an inspection task. Human Factors, 25, 391-399, 1983.

[7] Hamrol A., Kowalik D., Kujawińska A., Impact of chosen work condition factors on quality of manual assembly process, Human Factors and Ergonomics in Manufacturing, 21, 2, March/April 2011, item: 3331, pp. 156-163, 2011.

[8] Jo Y-D., Park K-S., Dynamic management of human error to reduce total risk, Journal of Loss Prevention, 16, 313-321, 2003.

[9] Kalaykov I, Wide P., Intelligent Feature Estimation, Based on Human's Perceptual Features, SCIMA, International Workshop on Soft Computing Techniques, Measurements and Related Applications, 2003.

[10] Drury C.G., Karwan M.H., Vanderwarker D.R., The two-inspector problem, IIE Transactions, 18, 174$181,1986$.

[11] Fox J.G., Ergonomics contribution to subjective inspection in industrial quality control, The Production Engineer, 1975.

[12] Raz T., Littchwager J.M., Ten measures of Inspection Performance, Jurnal of Quality Technology, 21, 2, 1989 .

[13] Więcek-Janka E., Decisions and games, Publishing House of Poznan University of Technology, 2011.

[14] Więcek-Janka E., Psycho-profile of Polish Microentrepreneur [in Polish: Sylwetka psychofizyczna polskiego Mikroprzedsiębiorcy], Ekonomika i Organizacja Przedsiębiorstwa, p. 116-120, 2007. 